\title{
If You Write It Better, You Will Say It Better
}

\author{
COMMUNICATION CORNER No. 16
}

\author{
by Philip Yaffe
}

\section{Editor's Introduction}

Each "Communication Corner" essay is self-contained; however, they build on each other. For best results, before reading this essay and doing the exercise, go to the first essay "How an Ugly Duckling Became a Swan," then read each succeeding essay.

Preparing a good text for reading and preparing a good text for speaking are often considered to be unrelated activities. This is incorrect. A good text for reading and a good text for speaking are distinct, but they are not alien. They are complementary. 


\title{
If You Write It Better, You Will Say It Better
}

\author{
COMMUNICATION CORNER No. 16
}

\author{
by Philip Yaffe
}

It should come as no surprise that if you write better, you will also speak better. This is because the fundamental principles of good writing-clarity, conciseness, density, inverted pyramid, 5Ws \& $\mathrm{H}$, etc. - are identical to the fundamental principles of good speaking.

Nevertheless, writing and speaking are distinct disciplines. Thus, while the principles are the same, how to effectively apply them to speaking must be closely examined.

\section{HOW WRITING AND SPEAKING ARE SIMILAR}

\section{Essential attitude}

\section{Expository Writing Attitude}

No one wants to read what you write.

\section{Expository Speaking Attitude}

No one wants to hear what you say.

While less true for speaking than for writing (see "How Writing and Speaking Are Different" below), in both cases your primary task-before anything else-is to give your readers and listeners reasons why they should be interested in the information you are about to give them.

\section{Essential approach}

Writing

Organize information to generate interest.

Speaking

Organize information to generate interest. 
Speaking in public obviously requires a different degree of mastery of the language than does writing. Nevertheless, the essential approach is identical.

For both writing and speaking, it is of course still necessary to be:

- Clear: effectively use the three elements of clarity

- Concise: effectively use the two elements of conciseness

- Dense: effectively use the two elements of density.

You should also make full use of the inverted pyramid-i.e. a clear, concise, and dense lead (introduction)-then the inverted pyramid technique, and the $Q$ \& $A$ technique to develop the body of each section of your presentation.

\section{HOW WRITING AND SPEAKING ARE DIFFERENT}

The differences between writing and speaking are rather subtle. They arise from the fact that readers and listeners have somewhat different mindsets.

\section{Essential attitude}

\section{Expository Writing Attitude}

No one wants to read what you write.

It is safe to assume when readers pick up an expository text, their initial attention is rather low. Since they probably do not want to read it, they are not fully concentrated on the task in hand.

\section{Expository Speaking Attitude}

No one wants to hear what you say.

Although listeners may not want to hear what you say, nevertheless they have made the effort to come together with you. For at least the first few minutes, therefore, they are likely to be totally focused on your presentation. Make good use of this initial high attention, because it is fragile and can rapidly dissipate. (See "Listener Attention" below.)

There is no difference between writing and speaking with regard to "clarity." However, there are slight but important differences with regard to "conciseness" and "density." 


\section{Clarity $\left(C_{L}=E D E\right)$}

Remember, clarity means:

1. Emphasize what is of key importance

2. De-emphasize what is of secondary importance

3. Eliminate what is of no importance

Whether you are writing or speaking, clarity remains imperative. Indeed, there is nothing more important.

Conciseness $\left(C_{0}=L S\right)$

Remember, conciseness means as:

1. Long as necessary

2. Short as possible

Long as necessary. Whether you are writing or speaking, you must still be as long as necessary. Whatever your time constraint, it makes no sense to leave out important information necessary for clarity. The inevitable result is that you will either confuse your listeners or leave them dissatisfied. One way or another you must be certain that you include in your presentation everything that is needed to make it clear.

So, what do you do when time is limited?

Ideally, you should seek more time. If the need for additional time is properly explained to the person in charge, it may very well be granted. If not, the following could help:

\section{Never cut out anything of key importance}

If key ideas are sacrificed, you might as well not give the presentation at all.

\section{Reduce things of secondary importance}

You might think that you need about 40 seconds to relate a piece of secondary information, but on reflection you may find that you could do an adequate job in 30 or even 25 seconds.

\section{Eliminate some things of secondary importance}


Suggesting this is not sacrilege. If you have three pieces of secondary information to support a key idea, using only two of them could be just as effective. Eliminating one of them could save precious time.

Carefully review your material. Certain pieces of information you have already decided to use may in fact be borderline; your judgment about whether they are of secondary importance or no importance could have gone either way. If you have any doubts, eliminate them.

Short as possible. With writing, we saw that any words beyond the minimum needed to be "as long as necessary" damage clarity. We also saw that expository writing should give information to readers as rapidly as possible, because this is what they want.

With speaking, listeners are not in quite such a hurry. They may not admit it, but in addition to being informed they also want to be entertained. To be fully effective, oral presentations need to be both expository and creative. This is why a pleasant voice, good eye contact, good body language, i.e. anything that makes the presentation a more enjoyable experience, are useful to oral success.

But let's not exaggerate their influence. The single most important thing you need in order to be a successful speaker is enthusiasm.

Passion for one's subject is infectious; listeners respond. If you make it clear that you are deeply committed to what you are saying, all the behavioral aspects of an oral presentation, however useful, will fade into the background.

\section{Density (D = PL)}

Remember, density means:

\section{Precise information}

2. Logically linked.

Precise information is crucially important in both writing and speaking, and for the same reasons:

\section{- Listener confidence}

The more you seem to know about your subject, the more listeners will want to hear what you say. Using precise information generates this confidence and interest.

\section{- Mind control}


Precise information does not allow unpredictable interpretations. Therefore, the more precise information you use, the more firmly you control the listener's mind to go where you want it to go and not wander off into unknown territory.

But be careful. However much they resemble each other, reading precise information and listening to precise information are fundamentally different.

A reader can stop and think about a piece of information if they find it of special interest or skip over it if they find it of no interest.

A listener can do neither, because it is the speaker who controls the situation. When something in a presentation particularly arouses a listener's interest, it is the speaker who decides how much time will be spent on it. When the listener finds some part of the presentation dull and tedious, there is no escape. They can only sit through it, waiting for the speaker to move on to something more interesting.

How do you handle these important differences between writing and speaking? Here are some suggestions.

\section{Prepare the listeners}

Before giving a block of precise information, data, statistics, etc., tell the listeners why you are doing so. In other words: First make a general statement, then give the precise information needed to support it.

What you are in fact doing is creating "oral bullet points."

\section{Limit the amount of precise information}

Unlike readers, listeners cannot take hold of a piece of information and examine it. First it is there, then it is gone. Listeners will therefore more easily accept the validity of a general statement with less supporting information than they might demand in a text. Indeed, giving too much supporting information during an oral presentation can become tedious, and therefore counterproductive.

\section{Ensure related information is logically linked}

In writing, failure to make logical links clear is a serious fault; in speaking, it is close to a sin. The speaker has total control. If logical links are not instantaneously apparent, listeners have absolutely no possibility of making these vital connections themselves.

As in writing, the best way to ensure logical linkage is by putting related information as close together as possible, reinforced by a linking transition such as "Information $A$ naturally implies Information B because ...." 
If it is not possible to place them one immediately after the other, when the second element does appear, use a linking transition to alert listeners to their relationship.

Example: "A few moments ago we looked at Information A. It should now be no surprise that Information B is a necessary consequence of Information A . . ."

\section{LISTENER ATTENTION}

As noted earlier under "essential attitude," it is reasonable to assume high initial listener attention at the beginning of an oral presentation, but we must not allow this advantage to dissipate. To gain most profit from it, we must make a fundamental distinction between how readers behave and how listeners behave.

When you sit down to read a text, chances are you try to isolate yourself from noise and other distractions. If someone interrupts you, you might ask them to come back later when you have finished what you are doing. In large measure, readers control their reading environment.

Listeners have no control over their environment. If someone nearby starts making comments, listeners could be distracted. If someone starts coughing, listeners could be distracted. If someone enters the room, listeners could be distracted. If someone leaves the room, listeners could be distracted. And so on.

Each time listeners are distracted, you as the speaker lose some precious attention. What can you do to prevent this from happening?

\section{- Exercise your control}

You may not be able to eliminate distractions, but you have it in your power to significantly reduce them.

1. The first thing is to rivet the listeners' attention on what you are saying by being certain that it is clear, concise, and dense. If each listener can easily understand and appreciate the importance of your words, distractions will be less intrusive, and loss of mind control will be reduced.

2. Second, you can support your presentation with well-designed visual aids. Attention goes where the eye goes. A well-conceived series of slides can do wonders to diminish the power of distractions and maintain mind control (keeping listeners thinking about what you want them to think about when you want them to think about it). 
3. Finally, you can ask questions. In my courses and workshops, I always designate key moments to engage listeners by challenging them in this way. For example:

- First, I define the appropriate attitude for a creative writer as, "Everyone wants to read what I am going to write." Then I ask what would be the appropriate attitude for an expository writer. A few timid volunteers usually offer their opinions, and usually one of them finally answers, "No one wants to read what I am going to write." If not, I give them the answer and then explain it.

- Another good moment to ask a question occurs during the definition of clarity. I give the listeners the first two elements (emphasize what is of key importance, deemphasize what is of secondary importance). I then ask, "What do you suppose the third element would be?" Someone almost always gives the correct answer: "Eliminate what is of no importance."

Asking questions not only helps maintain mind control, it memorably impresses key ideas on the listeners - a significant advantage.

\section{MATHEMATICAL MAGIC: THE LIE DETECTOR}

In the previous installment, I showed you a card trick so simple that it is difficult to imagine most people wouldn't immediately figure it out. However, as virtually every magician will explain, most tricks to some extent depend on distraction and misdirection. This trick almost totally depends on distraction and misdirection. In particular, it depends on the story you tell.

\section{What You Say}

"A psychologist friend recently told me that when someone is trying to conceal important information, you can often tell by a subtle change in their voice. I am going to use an ordinary deck of cards to see if my psychologist friend's technique really works. I am still a novice at this, so if you don't mind, I'm first going to remove all the jacks, kings, and queens from the deck."

Remove all the jacks, kings, and queens. Hand the deck to the participant and ask him to shuffle the cards as much as he wants. Then, while your back is turned, ask him to pick any card he wants, memorize it, and put it on top of the deck.

You turn around and say, "Have you chosen a card and put it on the top of the deck? Good. It's important that you have the card fixed firmly in your mind. So, to be certain, I will turn my back again. To ensure that the card is fixed firmly in your mind, I want you to take the same number of cards as the value of your chosen card from the bottom of the deck and put them on the top 
of the deck. For instance, if your card is a five, you would take five cards from the bottom of the deck and put them on the top of the deck. Clear? Good."

You turn your back and the participant does as instructed. You then turn around and take the deck in your hand.

"Now I am going to deal out the cards face up one by one. Each time I deal out a card, I want you to say its value and suit aloud. There should be a subtle difference in your voice when we get to your chosen card. I'm going to see if I can detect it."

Let's say the participant has chosen the 3 of spades. You start dealing out the cards face up and the participant names each card as you do. When you deal out the 3 of spades, you hesitate a moment and say, "Will you please repeat that?" He does, and you triumphantly say, "That's your card, isn't it?" And it is!

\section{What You Do}

You deal out the first card face up and the participant names it. While he is doing this, in your mind you think "zero." You then deal out the next card face up and the participant names it. In your mind you think "one." And so on. When the value of the dealt card matches the number you have in your mind, this is the chosen card.

For example, suppose the participant chooses the 3 of spades. You deal out the first card face up. The participant names it (say it's the 6 of clubs) and you think "zero." You deal out the second card face up, which the participant names and you think "one." You deal out the next card, which the participant names and you think "two." You deal out the next card and you think "three," which the participant names as the 3 of spades. Since you are now thinking "three," this is the chosen card.

\section{Why It Works}

If you stop to think about it, the secret is almost obvious. The participant first chooses a card ( 3 of spades) and puts it on the top of the deck. He then takes the same number of cards as the value of the chosen card (three) from the bottom of the deck and puts them on top. This means that the chosen card 3 will now be the fourth card down in the deck. You now deal out the cards face up one by one while in your head you count zero, one, two. The next card you deal out will be a three while at the same time you count three in your head. They match, so this is the chosen card.

\section{Caution}

It sometimes happens that you will get a premature match. In our example, you deal out a 6 and you count "zero," then you deal out an 8 and you count "one," next you deal out a 2 and you count "two." By chance, there is a match, so you say that this is the chosen card. But it isn't, 
because the chosen card is a 3 . This kind of coincidence is quite rare, but not impossible. When it happens, simply say, "I'm sorry, I'm still rather new at this. Let's continue and see if I can do better."

You deal out the next card, which is a 3 and, in your head, you count "three." Once again there is a match. This time it's the correct one, and everyone is amazed.

There is another version of the lie detector trick that allows you to avoid this slight embarrassment. You tell the same story about being able to detect when someone is trying to conceal important information by a subtle change in their voice. However, this time you deal out 16 cards face up in a square array (four by four). You do this by holding the cards face down in your hand, then turning over four cards face up in a horizontal row of four cards, next a second horizontal row of four face-up cards, etc.

$\begin{array}{cccc}x & x & x & x \\ x & x & x & x \\ \ldots & \ldots & \ldots & \ldots \\ \ldots & \ldots & \ldots & \ldots\end{array}$

Ask the participant to think of any one of the face-up cards on the table (say the 3 of spades) and to fix it firmly in his mind.

"Have you chosen a card? To help you fix it firmly in your mind, please point to the vertical column where it is located."

Say he points to the second vertical column from the left. You pick up the first column on the left and put it in your hand face up. Next, pick up the second column from the left (the one with the chosen card) and put it in your hand face up. Then the third column, then the fourth column.

Turn the cards over and deal them out again in left to right rows face up. Since you picked up the column containing the chosen card second, you know that it will now be one of the four cards in the second row. Ask the participant to point to the column where his chosen card is now located. Say he tells you the third column from the left. The second card down in the column will be the chosen card.

$\begin{array}{cccc}\mathbf{x} & \mathrm{x} & \mathrm{x} & \mathrm{x} \\ \mathbf{x} & \mathrm{x} & \mathbf{C} & \mathrm{x} \\ \ldots & \ldots & \ldots & \ldots \\ \ldots & \ldots & \ldots & \ldots\end{array}$


Since you now know the chosen card is the 3 of spades, you can pick up the cards in any order you want. Once they are back in your hand, you can even shuffle them or ask the participant to shuffle them.

"Now I am going to deal out the cards face up one by one. Each time I deal out a card, I want you to say its value and suit aloud. There should be a subtle difference in your voice when we get to your chosen card. I'm going to see if I can detect it."

When you deal out the 3 of spades, you hesitate a moment and say, "Will you please repeat that?" He does, and you triumphantly say, "That's your card, isn't it?" And it is!

\section{HOMEWORK: Retrospective to Communication Corner No. 15}

The homework for CC14 and CC15 constituted the same assignment in two parts. Fundamentally, you were given a number of criteria for designing effective slides. You were asked to:

- Check any slides you yourself may have produced in the past to see how closely they conform to these criteria. Be critical. The fact that you designed them and may have expended considerable time and energy doing so is irrelevant. If they don't work for the audience, they don't work. Whatever your good intentions, the time and energy you spent, while laudable, is simply beside the point.

- Whenever you attend a presentation that includes slides, check them to see how closely they conform to these criteria. Chances are you will find many of them do not. More importantly, you will probably find that this failure deeply damages the presentation. Fix this thought firmly in mind and keep it uppermost in your mind whenever you prepare slides for you own presentations.

- Go to the recommended web site to view a Steve Jobs presentation and admire how it was done by a master, with incredible results.

- Above all, never forget that there is no such thing as a "slide presentation." Slides only support the presentation; they should never be confused for the presentation itself.

If you have faithfully done these things, you should now be firmly convinced that properly designed slides advance a presentation while poorly designed slides hinder it. So, any extra time needed to produce good slides is time well spent.

\section{CURRENT HOMEWORK}


I normally don't approve of rote learning, i.e. memorizing things word for word. However, there are exceptions. Sometimes key ideas seem so simple or self-evident that, believing they have been fully grasped, people internalize them and push them to a subconscious level.

However, simple or self-evident ideas are often perceived this way because they harbor profound truths. Thus, internalizing them to the point of the subconscious can diminish their practical impact.

It has been my experience that while applying key ideas almost automatically, the best writers and speakers every so often bring these ideas to the conscious level to ensure they aren't forgetting or minimizing or overlooking something important. I know I certainly do this, and I recommend that you do so too.

Therefore, as homework I enjoin you to learn and remember certain key ideas word for word so you can call on them word for word whenever you feel the need to do so.

Here are the key ideas I believe you should know both consciously and subconsciously.

- Expository Writing Attitude

No one wants to read what you write

- Expository Speaking Attitude

No one wants to hear what you say

- Precise definition of Clear $\left(\mathbf{C}_{\mathrm{L}}=\mathbf{E D E}\right)$

- Precise definition of Concise $\left(\mathbf{C}_{0}=\mathbf{L S}\right)$

- Precise definition of Dense $(\mathbf{D}=\mathbf{P L})$

- Inverted pyramid: key information grouped at the top; secondary information (details) flow towards the bottom

- 5 Ws \& H (who, what, when, where, why, how)

- A series of short sentences often gives less information than a well-crafted longer one because the short sentences don't show the links between key elements.

- Hot spots: Words at the beginning and at the end of a sentence have stronger emphasis than those in the middle.

- First write like you speak; then write like you write 
- Yaffe's Law: If you give people what they want first, they are likely to accept anything else you want them to have. If you give them what you want first, chances are they won't accept anything at all.

- Text is visual. Used as Steve Jobs did, text draws 100 percent audience attention. With "text visuals," there are no extraneous details to dilute audience attention.

- Silence is golden-especially when you need to say something important.

- There is no such thing as a slide presentation. Slides only support the presentation; they should never be confused for the presentation itself.

- If you ever feel that what you are showing is becoming more important than what you are saying, delete the slides, tear up your speech, and start over again.

\section{About the Author}

Philip Yaffe was born in Boston, Massachusetts, in 1942 and grew up in Los Angeles, where he graduated from the University of California with a degree in mathematics and physics. In his senior year, he was also editor-in-chief of the Daily Bruin, UCLA's daily student newspaper. He has more than 40 years of experience in journalism and international marketing communication. At various points in his career, he has been a teacher of journalism, a reporter/feature writer with The Wall Street Journal, an account executive with a major international press relations agency, European marketing communication director with two major international companies, and a founding partner of a specialized marketing communication agency in Brussels, Belgium, where he has lived since 1974 . He is the author of more than 20 books, which can be found easily in Amazon Kindle.

DOI: $10.1145 / 3344272$ 